\title{
A Mouse Peritonitis Model for the Study of Glycopeptide Efficacy in GISA Infections
}

\author{
ALEJANDRO DOMENECH, ${ }^{1}$ SANDRA RIBES,${ }^{1}$ CARMEN CABELLOS,${ }^{1} \mathrm{M}$. ANGELES DOMÍNGUEZ, ${ }^{2}$ \\ ABELARDO MONTERO,${ }^{1}$ JOSEFINA LIÑARES,${ }^{2}$ JAVIER ARIZA, ${ }^{1}$ and FRANCESC GUDIOL ${ }^{1}$
}

\begin{abstract}
In recent years, the emergence of Staphylococcus aureus strains with reduced susceptibility to glycopeptides has raised considerable concern. We studied the efficacy of vancomycin and teicoplanin, as well as cloxacillin and cefotaxime, against the infection caused by four $S$. aureus strains with different glycopeptide and $\beta$-lactam susceptibilities (strains A, B, C, and D; MICs for vancomycin of $1,2,4$, and $8 \mu \mathrm{g} / \mathrm{ml}$ respectively), using a modified model of mouse peritonitis. This optimized model appeared to be straightforward and reproducible, and was able to detect low differences in bacterial killing between antibiotics and also between different $S$. aureus strains. Bactericidal activities in peritoneal fluid for vancomycin, teicoplanin, cloxacillin, and cefotaxime decreased from $-2.98,-2.36,-3.22$, and $-3.57 \log _{10} \mathrm{cfu} / \mathrm{ml}$, respectively, in infection by strain $\mathrm{A}$ (MICs for vancomycin and cloxacillin of 1 and $0.38 \mu \mathrm{g} / \mathrm{ml}$, respectively) to $-1.22,-0.65,-1.04$, and +0.24 in peritonitis due to strain D (MICs for vancomycin and cloxacillin of 8 and $1,024 \mu \mathrm{g} / \mathrm{ml}$ ). Our data confirm the superiority of $\boldsymbol{\beta}$-lactams against methicillin-susceptible $S$. aureus and show that bactericidal activity of glycopeptides decreases significantly with slight increases in MICs; this finding suggests a reduced efficacy of glycopeptides in the treatment of serious glycopeptide-intermediate $S$. aureus infections.
\end{abstract}

\section{INTRODUCTION}

G LYCOPEPTIDES ARE CONSIDERED the antibiotics of choice for the treatment of moderate to severe methicillin-resistant Staphylococcus aureus (MRSA) infections. However, the emergence of $S$. aureus strains with decreased susceptibility to these antibiotics is a matter of concern. . $, 3,9,10,12,20,29,35,36^{\text {Although }}$ the clinical relevance of glycopeptide-intermediate $S$. aureus (GISA) is controversial due to the lack of controlled studies, the poor outcome obtained using vancomycin in some difficultto-treat infections such as endocarditis or orthopedic surgical infections ${ }^{1,5}$ suggests that glycopeptide therapy may be suboptimal in this setting. To date, experimental studies assessing the best treatment of GISA infections have been scarce and inconclusive. ${ }^{5}$ Rabbit endocarditis or foreign body infection in rats or mice have been mostly used to study $S$. aureus infections and alternative therapies. These models closely simulate the characteristics of the infection in humans and provide clear end points that allow statistical comparisons between different therapeutic regimens, but their implementation is complex and they involve a considerable investment of time and money. To evaluate effortlessly the in vivo efficacy of different antimicrobial treatments for MRSA and GISA infections, we have developed a modified model of mouse peritonitis, using clinical strains of $S$. aureus with different susceptibilities to $\beta$-lactams and glycopeptides. The mouse peritonitis model is straightforward, rapid, and easily reproducible, and has been widely used in testing antibiotics in vivo $8,11,13-16,18,23,26$; however, although it has been used for the study of $S$. aureus infections, ${ }^{11,16,18,23,26}$ only a few comparative therapeutic studies have been reported. In this particular study, we performed the standardization of the model and assessed the comparative efficacy of monotherapy with cloxacillin, cefotaxime, vancomycin, and teicoplanin against the infection caused by four $S$. aureus strains.

\footnotetext{
${ }^{1}$ Laboratory of Experimental Infection, Infectious Diseases Service, and ${ }^{2}$ Microbiology Department, Hospital Universitari de Bellvitge, Barcelona, Spain.

This work was presented in part at the 41st Interscience Conference on Antimicrobial Agents and Chemotherapy, Chicago, Illinois, December, 2001 [abstract no. 1653].
} 


\section{MATERIALS AND METHODS}

\section{Bacterial strains}

Four staphylococcal clinical strains with different susceptibilities to glycopeptides and $\beta$-lactams were studied. Strains HUB 954 (strain A), HUB 284 (strain B), and HUB 783 (strain C) were isolated in our hospital and strain Mu 50 (ATCC 700699) (strain D) was isolated in Japan in 1997 and described as the first GISA strain. ${ }^{10}$ Strain C, belonging to the Iberian clone, had heterogeneous resistance to vancomycin (HRV), growing on $4 \mu \mathrm{g} / \mathrm{ml}$ Müeller-Hinton plates with a frequency of subpopulations of $3.6 \times 10^{-6} \mathrm{cfu} / \mathrm{ml}^{1}$. MICs of strains A, B, $\mathrm{C}$, and $\mathrm{D}$ were determined by the standard macrodilution method. ${ }^{24}$ Values of MICs are shown in Table 1.

\section{Inoculum preparation}

Colonies from fresh overnight cultures on $5 \%$ blood agar plates were resuspended and grown for $4-6 \mathrm{hr}$ at $37^{\circ} \mathrm{C}$ in TSB medium. Immediately before inoculation, cultures in TSB were centrifuged and resuspended in sterile saline, adjusted to an optical density equal to $0.5 \mathrm{McFarland}\left(\sim 10^{8} \mathrm{cfu} / \mathrm{ml}\right)$ and then diluted to the appropriate size. Inoculum sizes from $10^{6}$ to $10^{8}$ $\mathrm{cfu} / \mathrm{ml}$ were tested.

\section{Mouse peritonitis model}

The animal studies were approved by the Ethical Committee for Animal Experiments at the University of Barcelona. The mouse peritonitis model was a modified version of a previously described protocol. ${ }^{8,13,14}$ Two different mouse strains were tested: Outbred, female, ICR CD-1 mice ( $\sim 8$ weeks; $\sim 30$ grams) and inbred, female, C57BL/6 mice ( $\sim 6$ weeks; $\sim 14-16$ grams). Mice were kept 10 to a cage and had food and water ad libitum. Inoculation was performed by intraperitoneal (i.p.) injection of $0.5 \mathrm{ml}$ of the inoculum with a 26-gauge syringe. The inoculum consisted of a staphylococcal suspension with $5 \%(\mathrm{wt} / \mathrm{vol})$ mucin in sterile saline, which enhances the basal virulence of bacteria by inhibiting the local macrophage system, and renders the mice susceptible to infection. In the first stage of the study, the experimental design was standardized, prior to the pharmacokinetic and antibiotic therapy studies. Mouse strain, inoculum size, and virulence of different bacterial strains were evaluated.

TABle 1. MICS ( $\mu \mathrm{G} / \mathrm{ML})$ OF $S$. AuREUS Strains Used in the STUdy

\begin{tabular}{llrrr}
\hline & \multicolumn{4}{c}{$M I C(\mu g / m l)^{\mathrm{a}}$} \\
\cline { 2 - 5 } Antibiotic & $\begin{array}{l}\text { Strain A } \\
(\text { MSSA })\end{array}$ & $\begin{array}{r}\text { Strain B } \\
(\text { MRSA })\end{array}$ & $\begin{array}{c}\text { Strain C } \\
(\text { HRV })\end{array}$ & $\begin{array}{r}\text { Strain D } \\
(\text { GISA })\end{array}$ \\
\hline Cloxacillin & 0.38 & 512 & 1,024 & 1,024 \\
Cefotaxime & 0.5 & 1,024 & 1,024 & 2,048 \\
Vancomycin & 1 & 2 & 4 & 8 \\
Teicoplanin & 0.5 & 1 & 8 & 8 \\
\hline
\end{tabular}

${ }^{a}$ MSSA, Methicillin-susceptible S. aureus; MRSA, methicillin-resistant $S$. aureus; HRV, heterogeneous resistance to vancomycin; GISA, glycopeptide-intermediate $S$. aureus.
Different time points were tested to study the evolution of the infection and appropriate time points were set for starting therapy. Groups of mice were killed at 4, 8, 16, and $24 \mathrm{hr}$ postinoculation to obtain blood and peritoneal fluid (PF) samples as described below. Bacterial counts and bacteremia were determined for each mouse and time point. Mortality was also assessed.

\section{Sample collecting and processing}

At each time point, for all experiments, mice were anesthetized i.p. with $40 \mu \mathrm{l}$ of ketamine/xylazine $10: 1(100 \mathrm{mg} / \mathrm{kg}$ Ketamine and $10 \mathrm{mg} / \mathrm{kg}$ Xylacine) and a peritoneal wash was performed by injecting $2 \mathrm{ml}$ of sterile saline i.p. followed by a 1-min external massage of the abdomen. Immediately, $0.1 \mathrm{ml}$ of blood was withdrawn by cardiac puncture, and animals were then killed by cervical dislocation. The abdomen was opened and $0.2 \mathrm{ml}$ of PF was recovered from the peritoneum using an aseptic technique. PF samples were used to perform direct and 10 -fold diluted cultures, which were plated $(0.1 \mathrm{ml})$ on $5 \%$ sheep blood TSA plates and incubated for $24 \mathrm{hr}$ at $37^{\circ} \mathrm{C}$ to determine bacterial counts. The detection limit using this method was $10^{1} \mathrm{cfu} / \mathrm{ml}$; a value of $0.9 \mathrm{log} \mathrm{cfu} / \mathrm{ml}$ was assigned to the first sterile culture and 0 to the subsequent ones. To avoid carryover antimicrobial agent interference, the sample was placed on the plate in a single streak down the center and allowed to absorb into the agar until the plate surface appeared dry; the inoculum was then spread over the plate. Plates were incubated overnight at $37^{\circ} \mathrm{C}$. Blood cultures were also performed. Immediately after cardiac puncture, blood samples (100 $\mu \mathrm{l})$ were cultured in Trypticase soy broth for $24 \mathrm{hr}$ at $37^{\circ} \mathrm{C}$, and then 100 $\mu \mathrm{l}$ of the cultured broth were plated in TSA plates and incubated again for $24 \mathrm{hr}$ to assess bacterial growth. Bacteremia was expressed on the basis of blood cultures. Mortality was also expressed qualitatively.

\section{Pharmacokinetics}

Pharmacokinetic studies were performed to select dose regimens that result in serum concentrations similar to those in humans. All antimicrobials were administered subcutaneously. Groups of 20-22 healthy mice were used for each antibiotic pharmacokinetic study. A single weight-adjusted dose of the antibiotic was administered to each animal, following previous pharmacokinetic experimental studies. ${ }^{15,19,22,27,28,31,37,38}$

After antibiotic administration and at different time points, sets of 3 animals were anesthetized i.p. with appropriate doses of ketamine/xylacine, and blood samples $(\sim 400-500 \mu \mathrm{l})$ were obtained by an incision in the periorbital plexus of the eye. Blood was centrifuged and serum stored at $-80^{\circ} \mathrm{C}$ until analysis. Pharmacokinetic and pharmacodynamic (PK and PD) parameters were obtained by a computer-assisted method (PK Functions for Microsoft Excel. J. I. Usansky, A. Desai, and D. Tang-Liu, Department of Pharmacokinetics and Drug Metabolism, Allergan, Irvine, CA 92606) after determination of antibiotic concentration at the different time points. The parameters calculated were: peak drug concentration in serum $\left(C_{\max }\right)$, elimination half-life $\left(T_{1 / 2}\right)$, area under the concentration-time curve (AUC), inhibitory quotient (IQ; IQ $=C_{\max } / \mathrm{MIC}$ ), and time above the MIC of the drug concentration in serum $(\mathrm{T}>$ MIC). Based on previous studies, ${ }^{6,15,16}$ human data, ${ }^{7,21,30}$ and 
the PK and PD parameters obtained, doses administered to mice were finally selected: vancomycin $30 \mathrm{mg} / \mathrm{kg}$ per $4 \mathrm{hr}$ (daily dose of $180 \mathrm{mg} / \mathrm{kg}$ ), teicoplanin $40 \mathrm{mg} / \mathrm{kg}$ per $24 \mathrm{hr}$ (daily dose of $40 \mathrm{mg} / \mathrm{kg}$ ), cloxacillin $160 \mathrm{mg} / \mathrm{kg}$ per $2 \mathrm{hr}$ (daily dose of 1.6 $\mathrm{g} / \mathrm{kg}$ ), and cefotaxime $200 \mathrm{mg} / \mathrm{kg}$ per $2 \mathrm{hr}$ (daily dose of $2 \mathrm{~g} / \mathrm{kg}$ ).

\section{Therapeutic experiments}

Once the experimental design of the animal model was finalized, therapeutic experiments were performed. Four hours after inoculation, antibiotic therapy was initiated (hour 0). Vancomycin, teicoplanin, cloxacillin, or cefotaxime were administered as single regimens using the antibiotic schedule described above. At hour 0, 2 mice were killed and used as controls. Groups of 8 mice were then randomized to different therapeutic regimens $(n=6)$ and control group $(n=2)$. Antibiotic treatment or placebo was administered for $24 \mathrm{hr}$ and mice were killed at that time point to obtain blood and PF samples. Therapeutic experiments were repeated several times to achieve a minimum number of animals in all groups that allowed statistical analysis.

\section{Antibiotic assays}

Antibiotic assays were performed in duplicate. The serum concentrations of vancomycin and teicoplanin were determined by fluorescent polarization immunoassay (FPIA) using a TDx analyzer (ABBOTT CIENTÍFICA, S.A., Diagnostics Division, Costa Brava 13, 28034 Madrid, Spain); minimal detectable concentrations were $2.0 \mu \mathrm{g} / \mathrm{ml}$ for vancomycin and $1.7 \mu \mathrm{g} / \mathrm{ml}$ for teicoplanin. Serum concentrations of cloxacillin and cefotaxime were determined by the disk diffusion bioassay method, ${ }^{4}$ using S. aureus ATCC 29213 and E. coli ATCC 25922, respectively, as test organisms. The minimal detectable concentration was $0.5 \mu \mathrm{g} / \mathrm{ml}$ for cloxacillin and $1 \mu \mathrm{g} / \mathrm{ml}$ for cefotaxime.

\section{Statistical analysis}

All bacterial count data were checked for normal distribution (Kolmogorov-Smirnov test). Analysis of variance (ANOVA) with the Scheffé post hoc test was used to analyze multiple comparisons among therapeutic and control groups in every strain. Also comparisons among strains were made by using ANOVA (with Tukey post hoc test). The two-tailed Fisher's exact test was used for categorical data (survival, bacteremia). A linear regression was performed to assess correlation between in vivo vancomycin efficacy (bacterial count) and vancomycin susceptibility of the four strains (MICs).

\section{RESULTS}

\section{Standardization of the model}

An inoculum of $10^{6} \mathrm{cfu} / \mathrm{ml}$ of $S$. aureus strain A was used to compare mouse strains. The results of the immunocompetent inbred C57BL/6 mouse strain were more homogeneous than those of its outbred counterpart ICR CD-1. Dispersion in bacterial count data obtained at 4 and $24 \mathrm{hr}$ post-inoculation was significantly higher for ICR CD-1, whereas the mean bacterial count was higher for C57BL/6 (Fig. 1A). Bacteremia was higher in the C57BL/6 strain: $100 \%$ at 4 and $24 \mathrm{hr}$ post-inoculation for C57BL/6 and $71 \%$ and $80 \%$ at 4 and $24 \mathrm{hr}$, respectively, for ICR CD-1. Mortality at $24 \mathrm{hr}$ post-inoculation was $68 \%$ $(n=19)$ for C57BL/6 and 25\% $(n=8)$ for ICR CD-1. Inoculums from $10^{6}$ to $10^{8} \mathrm{cfu} / \mathrm{ml}$ of $S$. aureus strains A and C were compared in the C57BL/6 mice. The $10^{8} \mathrm{cfu} / \mathrm{ml}$ inoculum was rejected because mortality was $100 \%$ less than $16 \mathrm{hr}$ post-inoculation. Bacterial concentration at 4,8 , and $24 \mathrm{hr}$ post-inoculation did not show differences between $10^{6}$ and $10^{7}$ inoculums or between bacterial strains A and C. Bacteremia at $24 \mathrm{hr}$ post-inoculation was lower in mice infected with a $10^{6} \mathrm{cfu} / \mathrm{ml}$ inoculum $(72 \%)$ than in those infected with a $10^{7} \mathrm{cfu} / \mathrm{ml}$ inoculum (100\%, as mentioned above). Mortality was the parameter that varied most according to inoculum size: $8 \mathrm{hr}$ postinoculation, it was $72 \%(n=22)$ with the $10^{7} \mathrm{cfu} / \mathrm{ml}$ inoculum, but zero $(n=8)$ with the $10^{6} \mathrm{cfu} / \mathrm{ml}$ inoculum. At $24 \mathrm{hr}$ postinoculation, mortality was $100 \%(n=13)$ and $68 \%(n=19)$ for $10^{7}$ and $10^{6} \mathrm{cfu} / \mathrm{ml}$ inoculums, respectively (Fig. 1B). So the final experimental design for therapeutic studies included C57BL/6 mice and inoculum sizes of $5 \times 10^{6}$ to $5 \times 10^{7} \mathrm{cfu} / \mathrm{ml}$ depending on bacterial strain. Therapy was initiated $4 \mathrm{hr}$ postinoculation to avoid early mortality.

\section{Pharmacokinetics}

Pharmacokinetic and pharmacodynamic parameters of antibiotics used in the experiments are shown in Table 2. $T_{1 / 2} \mathrm{ob}-$ tained for $\beta$-lactams in mice is extremely short, and so the interdose time for these antibiotics was also very short. Although the serum peak was very high for cefotaxime and cloxacillin, $T>$ MIC for strains B, C, and D was 0 . Only for strain A did the $T>$ MIC of $\beta$-lactams reach $90-100 \%$. Vancomycin showed a high serum peak and $T>$ MIC ranging from $45 \%$ to $90 \%$ depending on the strain. Finally, teicoplanin achieved a very high AUC ( $>700 \mu \mathrm{g} / \mathrm{hr}$ per ml) due to its high serum peak and long $T_{1 / 2}$.

\section{Antibiotic efficacy: bacterial clearance in peritoneal fluid, bacteremia, and mortality}

Initial bacterial counts in PF (mean $\pm \mathrm{SD}$ ), corresponding to hour 0 of the control group for the different strains were: $7.62 \pm$ $0.37(n=23)$ for strain A, $7.05 \pm 0.43(n=15)$ for strain B, $7.04 \pm 0.55(n=28)$ for strain $\mathrm{C}$, and $7.02 \pm 0.35(n=13)$ for strain D. Bacteremia in control animals at 0 and $24 \mathrm{hr}$, expressed as percentage of positive blood cultures, was $100 \%$ for all strains. Mortality of control mice at $24 \mathrm{hr}$ differed according to strain: $55 \%$ for strain A, $22 \%$ for strain B, $62 \%$ for strain C, and $21 \%$ for strain D.

Bacterial clearance in PF after $24 \mathrm{hr}$ therapy for strains A, B, C, and D is shown in Fig. 2; $n=6$ for all therapeutic groups in all strains and $n \geq 12$ for 24-hr control groups of all strains. In strain A peritonitis, cloxacillin and cefotaxime were bactericidal at $24 \mathrm{hr}$. Vancomycin and teicoplanin showed slightly lower activity than $\beta$-lactams, although the difference was not significant. All therapies had significantly lower bacterial counts than the control group. All treated animals survived. Bacteremia at $24 \mathrm{hr}$ for cloxacillin and cefotaxime treatments was $0 \%$, but $25 \%$ for vancomycin and $100 \%$ for teicoplanin.

For strain B, vancomycin and teicoplanin achieved a significantly higher reduction in bacterial count than $\beta$-lactams, in which the decrease was minimal. There was no statistically sig- 

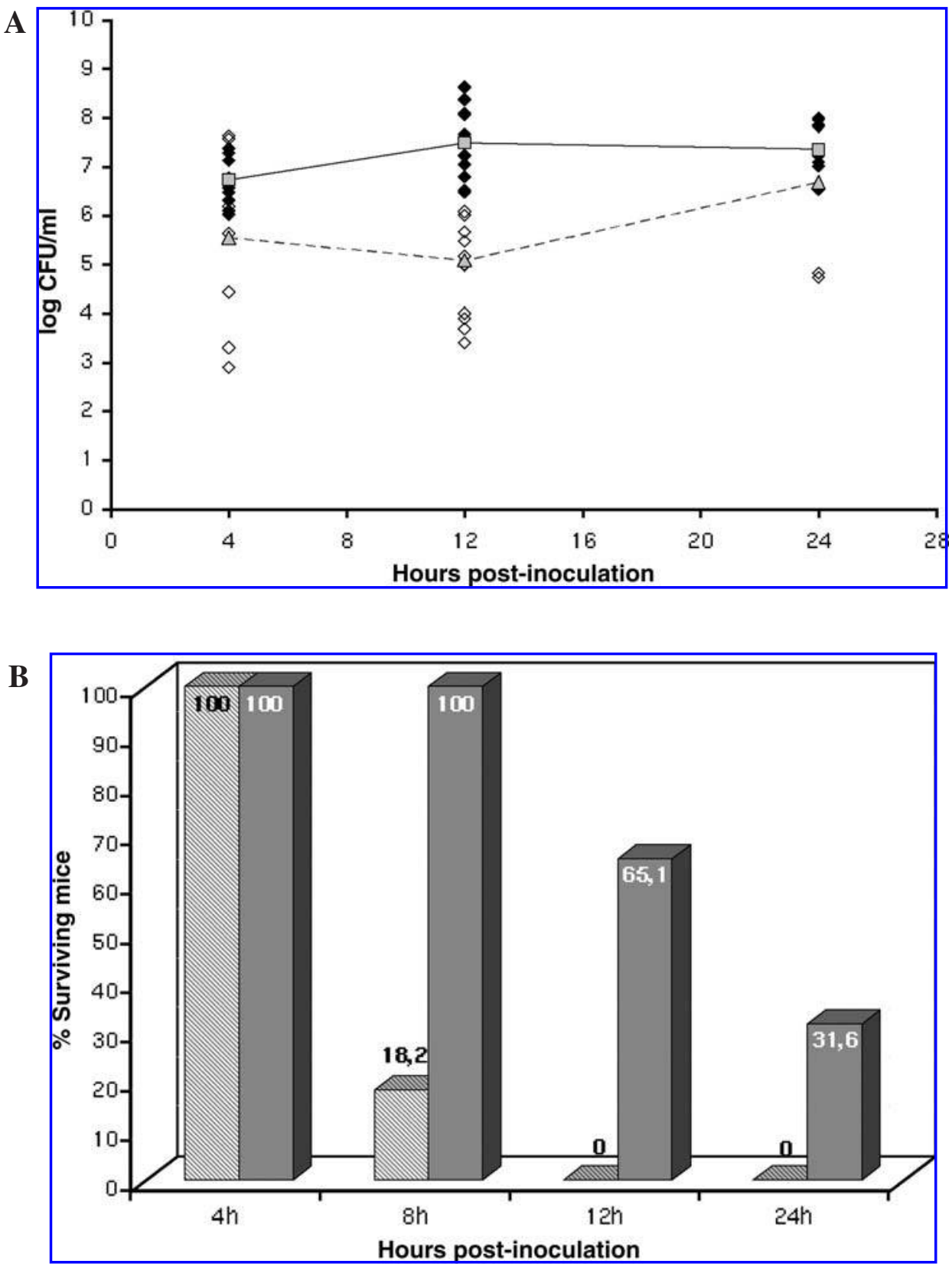

FIG. 1. (A) Comparison of data dispersion of bacterial count in PF between ICR (open symbols) and C57BL/6 (solid symbols) mouse strains at different time points. Each symbol represents one mouse. Solid squares and triangles linked by lines represent the respective means of C57BL/6 and ICR. (B) Survival at 4, 8, 12, and $24 \mathrm{hr}$ post-inoculation of C57BL/6 mice with peritonitis due to $S$. aureus. Comparison between $10^{7}$ (hatched columns) and $10^{6}$ (gray columns) cfu/ml inoculums.

nificant difference between the $\beta$-lactam and the control group. No mortality was observed in any treatment group. Vancomycin reduced bacteremia at $24 \mathrm{hr}$ to zero and teicoplanin to $50 \%$. Bacteremia fell to $80 \%$ with cefotaxime, but remained at $100 \%$ at $24 \mathrm{hr}$ with cloxacillin.

In strain C experiments, only vancomycin was able to reduce bacterial counts that differed significantly from those of the control group. It also differed significantly from cefotaxime, which showed an increase in bacterial count at $24 \mathrm{hr}$, and was totally ineffective. Mortality for cefotaxime-treated mice was $66 \%$, whereas survival was $100 \%$ in the other treatment groups. Cloxacillin and cefotaxime were not able to reduce bacteremia. Teicoplanin decreased bacteremia slightly to $83 \%$ and vancomycin reduced it to $33 \%$.

Finally, in strain D experiments, vancomycin showed only moderate activity, lower than that achieved in strain C. Teicoplanin reduced the bacterial count slightly, showing lower activity than cloxacillin, and less activity also than that achieved with strain $\mathrm{C}$. The activity of cloxacillin was slightly higher than that obtained for strains B and C. All treated animals sur- 
Table 2. Pharmacokinetic and Pharmacodynamic Parameters of Antibiotics Used in the Experiments

\begin{tabular}{|c|c|c|c|c|}
\hline \multirow[b]{2}{*}{ Parameter } & \multicolumn{4}{|c|}{ Antibiotics } \\
\hline & Cloxacillin & Cefotaxime & Vancomycin & Teicoplanin \\
\hline Dose & $160 \mathrm{mg} / \mathrm{kg}$ & $200 \mathrm{mg} / \mathrm{kg}$ & $30 \mathrm{mg} / \mathrm{kg}$ & $40 \mathrm{mg} / \mathrm{kg}$ \\
\hline$C_{\max }(\mu \mathrm{g} / \mathrm{ml})$ & 163.5 & 162.3 & 44 & 148 \\
\hline$t_{1 / 2}(\mathrm{hr})$ & 0.35 & 0.19 & 0.56 & 3.26 \\
\hline AUC $(\mu \mathrm{g} / \mathrm{hr}$ per ml) & 116.25 & 76.4 & 45.4 & 729 \\
\hline \multicolumn{5}{|l|}{$\mathrm{IQ}\left(C_{\max } / \mathrm{MIC}\right)$} \\
\hline Strain A & 430.13 & 324.68 & 44.01 & 296.20 \\
\hline Strain B & $<0.64$ & $<0.63$ & 22.01 & 148.10 \\
\hline Strain C & $<0.64$ & $<0.63$ & 11.00 & 18.51 \\
\hline Strain D & $<0.64$ & $<0.63$ & 5.50 & 18.51 \\
\hline \multicolumn{5}{|l|}{$t>\operatorname{MIC}(\mathrm{hr})[\%]$} \\
\hline Strain A & $3.4[>100]$ & $1.78[\sim 80]$ & 3.47 [87] & $25.94[>100]$ \\
\hline Strain B & $0[--]$ & $0[--]$ & $2.91[73]$ & $22.68[95]$ \\
\hline Strain C & $0[--]$ & $0[--]$ & 2.35 [59] & $12.91[54]$ \\
\hline Strain D & $0[--]$ & $0[--]$ & $1.79[48]$ & $12.91[54]$ \\
\hline
\end{tabular}

vived, except those treated with cefotaxime; cefotaxime was ineffective, and presented a mortality of $14 \%$ at $24 \mathrm{hr}$. Vancomycin and cloxacillin reduced bacteremia to $28.6 \%$, whereas teicoplanin and cefotaxime achieved no reduction.
Comparison of glycopeptide therapy between the four strains in the study is shown in Fig. 3; its efficacy was significantly lower with infections due to strains $\mathrm{C}$ and D (HRV, GISA) than with infections due to strains $\mathrm{A}$ and $\mathrm{B}$.

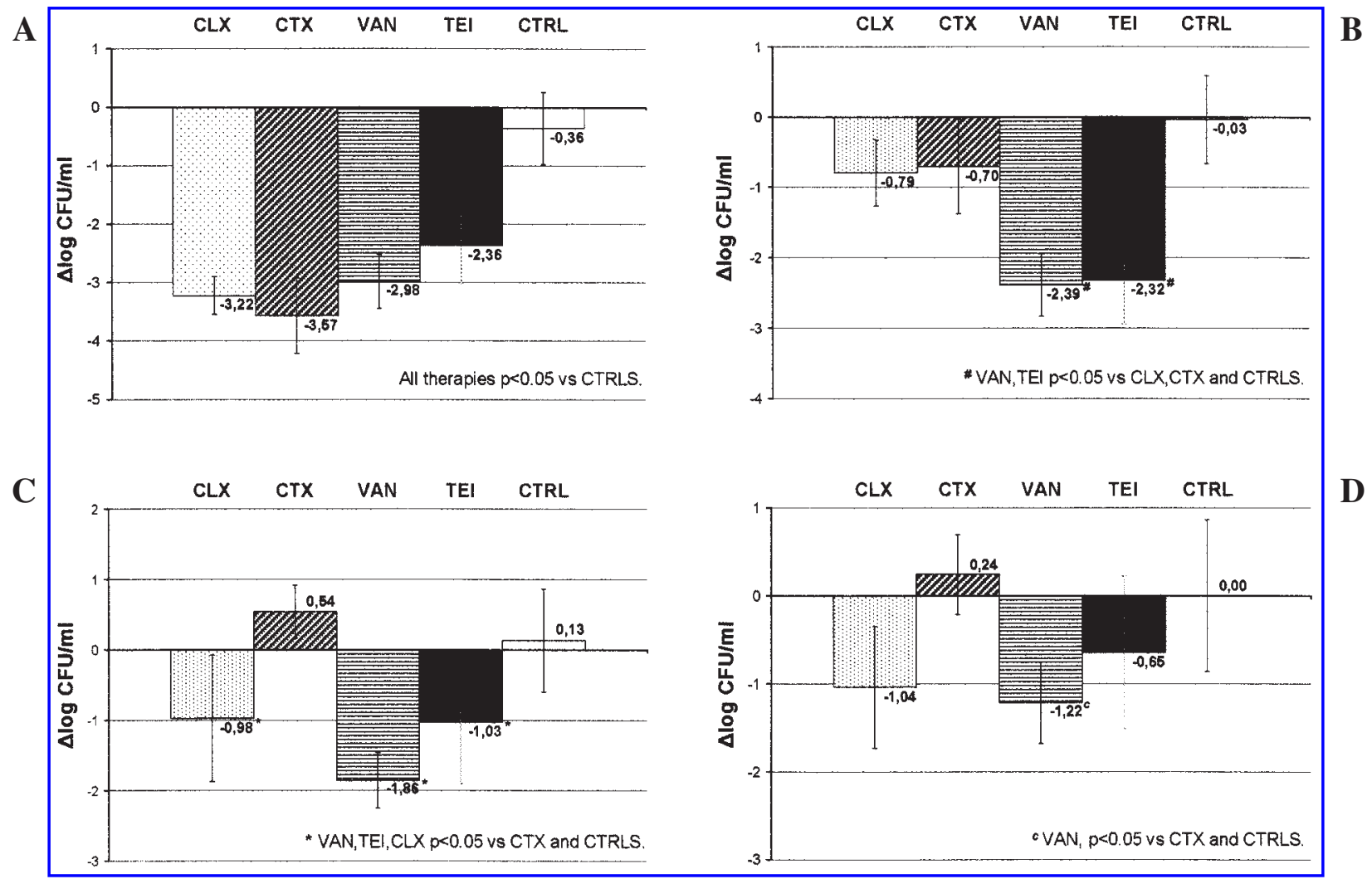

FIG. 2. Bacterial killing rates in peritoneal fluid after $24 \mathrm{hr}$ of therapy for strains A (A), B (B), C (C), and D (D). Results are expressed as differences in mean bacterial counts between the different groups at $24 \mathrm{hr}$ of treatment and controls at $0 \mathrm{hr}(\Delta \log 10 \mathrm{cfu} / \mathrm{ml}$ (24-0 hr). Mean bacterial counts $\pm \mathrm{SD}$ at $24 \mathrm{hr}$ for the different strains were, for strain A: CLX $4.40 \pm 0.32$, CTX 4.05 \pm 0.65 , VAN $4.64 \pm 0.46$, TEI $5.26 \pm 0.65$, and Control (CTRL) $6.95 \pm 0.62$; for strain B: CLX $6.26 \pm 0.47$, CTX 6.35 \pm 0.67 , VAN 4.66 \pm 0.44, TEI $4.73 \pm 0.63$, and Control (CTRL) $7.01 \pm 0.62$; for strain C: CLX $6.08 \pm 0.90$, CTX $7.59 \pm 0.38$, VAN 5.19 \pm 0.39 , TEI $6.02 \pm 0.88$, and Control (CTRL) 7.18 \pm 0.73 ; and for strain D: CLX $5.98 \pm 0.69$, CTX 7.26 \pm 0.45 , VAN 5.80 \pm 0.46 , TEI 6.37 \pm 0.87, and Control (CTRL) 7.02 $\pm 0.75 . n=6$ for all therapeutic groups and $n \geq 12$ for control groups at $24 \mathrm{hr}$. 
A

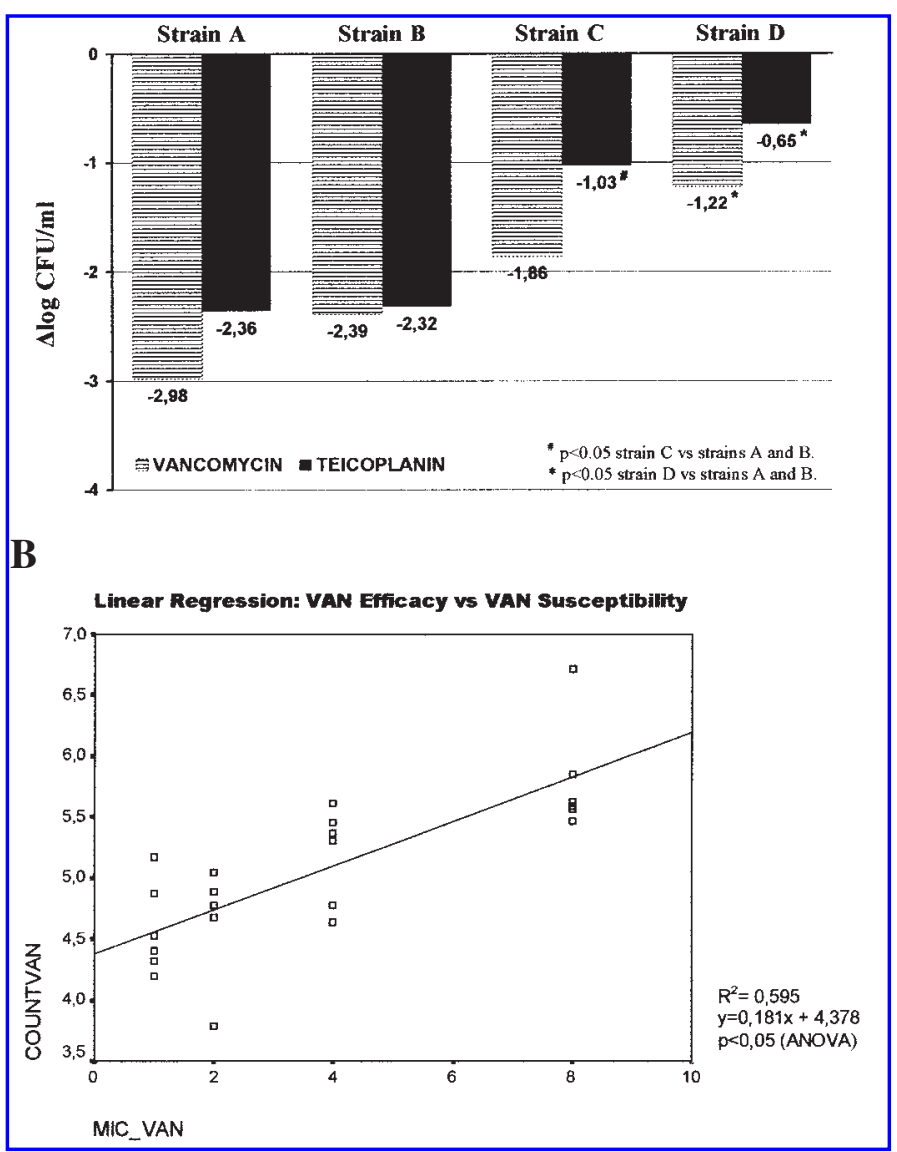

FIG. 3. (A) Comparison of vancomycin and teicoplanin bacterial killing rates at $24 \mathrm{hr}$ among $S$. aureus strains A, B, C, and D. Results are expressed as $\Delta \log _{10} \mathrm{cfu} / \mathrm{ml}(24-0 \mathrm{hr})$. Mean bacterial counts $\pm \mathrm{SD}$ at $24 \mathrm{hr}$ for the different strains were: strain A, VAN $4.64 \pm 0.46$, TEI $5.26 \pm 0.65$; strain B, VAN $4.66 \pm$ 0.44 , TEI $4.73 \pm 0.63$; strain C, VAN $5.19 \pm 0.39$, TEI $6.02 \pm$ 0.88 ; and strain D, VAN $5.80 \pm 0.46$, TEI $6.37 \pm 0.87 . n=6$ for all groups. (B) Linear regression between vancomycin susceptibility, expressed as the MIC of the different strains ( $x$ axis) and vancomycin efficacy, expressed as bacterial counts (log $\mathrm{cfu} / \mathrm{ml}$ ) of vancomycin-treated groups ( $y$ axis). Each point represents one mouse.

\section{DISCUSSION}

In general, previous experimental studies with the $S$. aureus mouse peritonitis model have not focused on comparison of different antibiotic regimens. We developed a modified version of the model previously described, evaluating variables involved in the experimental design to obtain a model that was sufficiently sensitive for detecting differences in efficacy among different antibiotic regimens. Results for mean bacterial count, bacterial count dispersion, and bacteremia suggested that the C57BL/6 mouse strain performed better, showing more susceptibility to infection and also providing more homogeneous findings. Among the different parameters used, the bacterial count of peritoneal fluid was the most useful to assess antibiotic efficacy, whereas survival was less sensitive for comparisons between different antibiotics in this model. Therefore, we sought an inoculum size that could produce a high bacterial count in peritoneal fluid, high bacteremia, and low mortality during the first hours after inoculation. While bacterial counts in peritoneal fluid of $7-8 \log _{10} \mathrm{cfu} / \mathrm{ml}$ and $100 \%$ bacteremia were found using inoculums of both $10^{6}$ and $10^{7} \mathrm{cfu} / \mathrm{ml}$, mortalities ranged from $21 \%$ to $62 \%$, depending on the strain, reflecting the virulence of the model. We therefore used 5-9 $\times$ $10^{6}$ as the inoculum size of choice for strain A and $1-5 \times 10^{7}$ $\mathrm{cfu} / \mathrm{ml}$ for strains $\mathrm{B}, \mathrm{C}$, and D to obtain a similar mortality rate. The mouse peritonitis model was highly reproducible, and it was easier to perform and cheaper than other models used in experimental $S$. aureus-related infections.

Antibiotic dosing regimens were chosen to obtain appropriate PK/PD parameters that simulate those in humans. ${ }^{6,7,21}$ Vancomycin at a dose of $30 \mathrm{mg} / \mathrm{kg}$ reached a good peak in mice serum (within the range of that in humans), with high IQ values for strains $\mathrm{A}$ and $\mathrm{B}$, within the recommended values for strain $\mathrm{C}$ and slightly below that value for strain $\mathrm{D}$. This dose was administered every $4 \mathrm{hr}$ (final dose of $180 \mathrm{mg} / \mathrm{kg}$ per day) to maintain a good $T>$ MIC value, which was high for strains $\mathrm{A}$ and $\mathrm{B}$ and below $50 \%$ of interdose time for strains $\mathrm{C}$ and $\mathrm{D}$. Efficacy of vancomycin decreased from strain A to D, showing a good correlation with the MICs of the different strains and the PK/PD parameters obtained. Teicoplanin at $40 \mathrm{mg} / \mathrm{kg}$ achieved a serum peak and trough similar to those in humans and, as expected from its long elimination half-life, showed a very high AUC. It could therefore be administered in a single daily dose. Higher IQs than vancomycin, (minimal $\sim 10$ for strain D) and $T>$ MIC from $>100 \%$ for strain A to $\sim 40 \%$ for strain D confirmed an optimal PK/PD profile, similar to that in humans.

Teicoplanin showed good efficacy for strains A and B, but only moderate for strains $\mathrm{C}$ and $\mathrm{D}$, in accordance with its pharmacodynamic profile, but with some differences with respect to vancomycin. Vancomycin showed slightly improved activity than teicoplanin in experiments with strains $\mathrm{A}$ and $\mathrm{B}$; this better efficacy is more evident for strains C and D although no significant differences were found between the two therapies. Thus, teicoplanin presented better PK/PD profiles than vancomycin, but it was not more effective in vivo, as others have already reported. ${ }^{27,38}$ It is interesting how this point becomes more apparent with GISA strains, in which teicoplanin therapy was clearly less effective than vancomycin. Recently, Pavie et al. have reported the impact of the GISA phenotype when using teicoplanin in therapy for experimental endocarditis, ${ }^{25}$ an observation that is in agreement with our results. High levels of protein binding and low penetration in some tissues have been proposed as possible causes for teicoplanin failure in some clinical and experimental infections. ${ }^{15,16,25}$

Cloxacillin and cefotaxime showed bactericidal efficacy in the treatment of peritonitis due to strain A, as was expected from their PK/PD profiles. On the other hand, vancomycin and teicoplanin showed good activity but were not bactericidal at $24 \mathrm{hr}$. Our results corroborate previous reports that glycopeptides are less bactericidal than $\beta$-lactams in the treatment of serious infections such as endocarditis. ${ }^{5,17,32}$ Cefotaxime and cloxacillin preserved a slight activity against strain B despite the fact that their $T>$ MIC was 0 , and, more surprisingly, cloxacillin retained a moderate activity against strains $\mathrm{C}$ and $\mathrm{D}$, a finding that was not consistent with its pharmacodynamic pa- 
rameters. A partial explanation for this observation may be the reciprocal loss of resistance to oxacillin in some strains as vancomycin MICs increase, as was previously described by Sieradzki and Tomasz. ${ }^{33,34}$ On the one hand, they noted that vancomycin-resistant $S$. aureus laboratory-derived mutants reduced $\beta$-lactam resistance as increased MICs of the glycopeptides; on the other, they reported that the acquisition of this resistance to vancomycin involves the change from the homogeneous to the heterogeneous methicillin-resistant phenotype. Thus, although hGISA and GISA strains used in our experiment were still highly resistant to methicillin on the basis of their MICs, we can hypothesize that the increasing in vivo efficacy of cloxacillin may be due to the emergence of subpopulations less resistant to methicillin, reflecting an early stage in the change from the homogeneous to the heterogeneous methicillin-resistant phenotype.

The efficacy of vancomycin and teicoplanin to treat peritonitis due to strains B, C, and D decreased progressively. Interestingly, percentages of bacteremia increased as killing rates achieved by glycopeptides decreased. Comparison of glycopeptide efficacy among the four strains showed that bactericidal activity decreased significantly with slight increases in glycopeptide MICs (Fig. 3A). The linear regression shown in Fig. 3B underscores this inverse linear relationship between vancomycin MIC and its efficacy in vivo. This result suggests that any decrease in glycopeptide susceptibility may have clinical implications, especially in the setting of difficult-to-treat infections such as endocarditis or orthopedic infection, as has been previously described. ${ }^{1,5}$ On the other hand, vancomycin keeps significant activity compared to controls in strains $\mathrm{C}$ and D (Fig. 3D). Although scarce, this remnant bacteriostatic activity could be relevant in the clinical setting, in which vancomycin can be still useful in relatively mild infections such as nonnecrotizing skin and soft tissue infections, but not in severe infections.

In conclusion, this mouse peritonitis model is straightforward and reproducible. It is able to detect low differences in bacterial killing among antibiotics and also among $S$. aureus strains with different methicillin and glycopeptide susceptibilities. Therefore, this model is particularly useful for comparing the efficacy of antibiotics against these strains. Although the results obtained with experimental infections must be interpreted with caution, our study suggests that heterogeneous resistance to glycopeptides and increases in glycopeptide MICs may be associated with a loss of efficacy in these antibiotics. These findings help to explain previous reports of therapeutical failures with infections due to HRV and GISA strains. This experimental model seems particularly well suited to the task of finding alternative treatments for these infections.

\section{ACKNOWLEDGMENTS}

We thank J.M. Ramón, from Hospital de Bellvitge, for his assistance in statistical analysis. This work was supported by a research grant from the Fondo de Investigaciones Sanitarias FIS 00/0156 from Ministerio de Sanidad, Spain. A. Domenech was supported by a grant from the Universitat de Barcelona, and S. Ribes and A. Montero were supported by grants from the Fun- dació August Pi i Sunyer. The study was performed without any financial support from laboratories.

\section{REFERENCES}

1. Ariza, J., M. Pujol, J. Cabo, C. Peña, N. Fernández, J. Liñares, J. Ayats, and F. Gudiol. 1999. Vancomycin in surgical infections due to methicillin-resistant Staphylococcus aureus with heterogeneous resistance to vancomycin. Lancet 353:1587-1588.

2. Centers for Disease Control and Prevention. 2000. Staphylococcus aureus with reduced susceptibility to vancomycin-Illinois, 1999. Morb. Mortal. Wkly. Rep. 48:1165-1167.

3. Centers for Disease Control and Prevention. 1997. Staphylococcus aureus with reduced susceptibility to vancomycin-United States, 1997. Morb. Mortal. Wkly. Rep. 46:765-766.

4. Chapin-Robertson, K., and S.C. Edberg. 1991. Measurements of antibiotics in human body fluids: techniques and significance. In V. Lorian (ed.), Antibiotics in laboratory medicine. Williams and Wilkins, New York, pp. 295-366.

5. Climo, W.M., R.L. Patron, and G.L. Archer. 1999. Combinations of vancomycin and $\beta$-lactams are synergistic against staphylococci with reduced susceptibilities to vancomycin. Antimicrob. Agents Chemother. 43:1747-1753.

6. Craig, W.A. 1998. Pharmacokinetic/pharmacodynamic parameters: rationale for antibacterial dosing of mice and men. Clin. Infect. Dis. 26:1-12.

7. Fekety, R. 1995. Vancomycin and Teicoplanin. In G.L. Mandell, J.E. Bennett, and R. Dolin (ed.), Principles and practice of infectious diseases, $4^{\text {th }}$ ed. Churchill Livingston, New York, pp. 346354.

8. Frimodt-Moller, N. 1993. The mouse peritonitis model: present and future use. J. Antimicrob. Chemother. 31(Suppl D):55-60.

9. Hiramatsu, K., N. Aritaka, H. Hanaki, S. Kawasaki, Y. Hosoda, S. Hori, Y. Fukuchi, and I. Kobayashi. 1997. Dissemination in Japanese hospitals of strains of Staphylococcus aureus heterogeneously resistant to vancomycin. Lancet 350:1670-1673.

10. Hiramatsu, K., H. Hanaki, T. Ino, K. Yabuta, T. Oguru, and F. C. Tenover. 1997. Methicillin-resistant Staphylococcus aureus clinical strain with reduced vancomycin susceptibility. J. Antimicrob. Chemother. 40:135-136.

11. Hirschl, A., G. Stanek, and M. Rotter. 1984. Effectiveness of cefamandole against methicillin-resistant strains of Staphylococcus aureus in vitro and in experimental infections. J. Antimicrob. Chemother. 13:429-435.

12. Kim, M. N., C.H. Pai, J.H. Woo, J.S. Ryu, and K. Hiramatsu. 2000. Vancomycin intermediate Staphylococcus aureus in Korea. J. Clin. Microbiol. 38:3879-3881.

13. Knudsen, J.D., N. Frimodt-Moller, and F. Espersen. 1995. Experimental Streptococcus pneumoniae infection in mice for studying correlation of in vitro and in vivo activities of penicillin against pneumococci with various susceptibilities to penicillin. Antimicrob. Agents Chemother. 39:1253-1258.

14. Knudsen, J.D., N. Frimodt-Moller, and F. Espersen. 1998. Pharmacodynamics of penicillin are unaffected by bacterial growth phases of Streptococcus pneumoniae in the mouse peritonitis model. J. Antimicrob. Chemother. 41:451-459.

15. Knudsen, J.D., K. Fuursted, F. Espersen, and N. FrimodtMoller. 1997. Activities of vancomycin and teicoplanin against penicillin-resistant pneumococci in vitro and in vivo and correlation to pharmacokinetic parameters in the mouse peritonitis model. Antimicrob. Agents Chemother. 41:1910-1915.

16. Knudsen, J.D., K. Fuursted, S. Raber, F. Espersen, and N. Frimodt-Moller. 2000. Pharmacodynamics of glycopeptides in the mouse peritonitis model of Streptococcus pneumoniae or Staphy- 
lococcus aureus infection. Antimicrob. Agents Chemother. 44: 1247-1254.

17. Levine, D.P., B.S. Fromm, and B.R. Reddy. 1991. Slow response to vancomycin or vancomycin plus rifampin in methicillin-resistant Staphylococcus aureus endocarditis. Ann. Intern. Med. 115:674-680.

18. Mannisto, P.T., H. Hanhijarvi, A. Havas, A. Vuorela, H. Komulainen, and V. Rauramaa. 1989. Efficacy of erythromycin acistrate (2'-acetyl erythromycin stearate) and erythromycin stearate in experimental infections in mice. J. Pharmacol. Exp. Ther. 250:1028-1033; erratum in J. Pharmacol Exp. Ther. 251: 1246-1247, 1989.

19. Mattie, H., L.C. Zhang, E. van Strijen, B.R. Sekh, and A.E. Douwes-Idema. 1997. Pharmacokinetic and pharmacodynamic models of the antistaphylococcal effects of meropenem and cloxacillin in vitro and in experimental infection. Antimicrob. Agents Chemother. 41:2083-2088.

20. McManus, J. 1999. Vancomycin resistant staphylococcus reported in Hong Kong. Br. Med. J. 318:626

21. Monroe, S.G., and R. Polk. 1999. Teicoplanin; vancomycin. In V.L. Yu, T.C. Merigan Jr., and S.L. Barriere (ed.), Antimicrobial therapy and vaccines. Williams and Wilkins, Baltimore, MD, pp. 978-981 and 1007-1018.

22. Nagano, R., K. Shibata, T. Naito, A. Fuse, K. Asano, T. Hashizume, and S. Nakagawa. 1997. Therapeutic efficacy of BO3482, a novel dithiocarbamate carbapenem, in mice infected with methicillin-resistant Staphylococcus aureus. Antimicrob. Agents Chemother. 41:2278-2281.

23. Nagl, M., P. Hengster, E. Semenitz, and W. Gottardi. 1999. The postantibiotic effect of N-chlorotaurine on Staphylococcus aureus. Application in the mouse peritonitis model. J. Antimicrob. Chemother. 43:805-809.

24. National Committee for Clinical Laboratory Standards. 2000. Methods for dilution antimicrobial susceptibility test for bacteria that grow aerobically. Approved standard, 5th ed., NCCLS Document M7-A5, vol. 20, no. 2. National Committee for Clinical Laboratory Standards, Villanova, PA.

25. Pavie, J., A. Lefort, MC. Ploy, L. Massias, F. Chau, L. Garry, F. Denis, and B. Fantin. 2003. Influence of reduced susceptibility to glycopeptides on activities of vancomycin and teicoplanin against Staphylococcus aureus in experimental endocarditis. Antimicrob. Agents Chemother. 47:2018-2021.

26. Pechere, J.C., B. Marchou, M. Michea-Hamzehpour, and R. Auckenthaler. 1986. Emergence of resistance after therapy with antibiotics used alone or combined in a murine model. J. Antimicrob. Chemother. 17 (Suppl A):11-18.

27. Peetermans, W.E., J.J. Hoogeterp, A-M. Hazekamp-van Dokkum, P. van den Broek, and H. Mattie. 1990. Antistaphylococcal activities of teicoplanin and vancomycin in vitro and in an experimental infection. Antimicrob. Agents Chemother. 34:1869-1874.

28. Pitkin, D.H., B.A. Mico, R.D. Sitrin, and L.J. Nisbet. 1986. Charge and lipophilicity govern the pharmacokinetics of glycopeptide antibiotics. Antimicrob. Agents Chemother. 29:440-444.
29. Ploy, M.C., C. Grelaud, C. Martin, L. de Lumley, and F. Denis. 1998. First clinical isolate of vancomycin-intermediate Staphylococcus aureus in a French hospital. Lancet 351:1212.

30. Sábada Díaz de Rada, B., J.R. Azanza Perea., E. García Quetglas, and J. Honorato Pérez. 1998. Glucopéptidos: vancomicina y teicoplanina. In Medicine 7 (72), Ediciones Doyma S. L., Barcelona, Spain, p. 3329-3336.

31. Sauve, C., E. Azoulay-Dupuis, P. Moine, C. Darras-Joly, V. Rieux, C. Carbon, and J. P. Bedos. 1996. Efficacies of cefotaxime and ceftriaxone in a mouse model of pneumonia induced by two penicillin- and cephalosporin-resistant strains of Streptococcus pneumoniae. Antimicrob. Agents Chemother. 40:2829-2834.

32. Small, P.M., and H.F. Chambers. 1990. Vancomycin for Staphylococcus aureus endocarditis in intravenous drug users. Antimicrob. Agents Chemother. 34:1227-1231

33. Sieradzki, K., and A. Tomasz. 1997. Inhibition of cell wall turnover and autolysis by vancomycin in a highly vancomycin-resistant mutant of Staphylococcus aureus. J. Bacteriol. 179:25572566.

34. Sieradzki, K., and A. Tomasz. 1999. Inactivation of the methicilli resistance gene mecA in vancomycin-resistant Staphylococcus aureus. Microb Drug Resist 5:253-257.

35. Sieradzki, K., R.B. Roberts, S.W. Haber, and A. Tomasz. 1999. The development of vancomycin resistance in a patient with methicillin-resistant Staphylococcus aureus infection. N. Engl. J. Med. 340:517-523.

36. Smith, T.L., M.L. Pearson, K.R. Wilcox, C. Cruz, M.V. Lancaster, B. Robinson-Dunn, F.C. Tenover, M.J. Zervos, J.D. Band, E. White, and W.R. Jarvis. 1999. Emergence of vancomycin resistance in Staphylococcus aureus. N. Engl. J. Med. 340:493-501.

37. Tateda, K., K. Takashima, H. Miyazaki, T. Matsumoto, T. Hatori, and K. Yamaguchi. 1996. Noncompromised penicillin-resistant pneumococcal pneumonia CBA/J mouse model and comparative efficacies of antibiotics in this model. Antimicrob. Agents Chemother. 40:1520-1525.

38. Torney, H.L., F.J. Balistreri, M.T. Kenny, and W.D. Cheng. 1991. Comparative therapeutic efficacy of teicoplanin and vancomycin in normal and in neutropenic mice infected with Staphylococcus haemolyticus. J. Antimicrob. Chemother. 28:261-269.

Address reprint requests to:

Dr. Alejandro Domenech

Infectious Diseases Service

Hospital Universitari de Bellvitge

c/Feixa Llarga $s / n$

08907 L'Hospitalet de Llobregat

Barcelona, Spain

E-mail: adomenech@bell.ub.es 


\section{This article has been cited by:}

1. L. Diaz, D. P. Kontoyiannis, D. Panesso, N. D. Albert, K. V. Singh, T. T. Tran, J. M. Munita, B. E. Murray, C. A. Arias. 2013. Dissecting the Mechanisms of Linezolid Resistance in a Drosophila melanogaster Infection Model of Staphylococcus aureus. Journal of Infectious Diseases 208:1, 83-91. [CrossRef]

2. Eun Young Choi, Jin Won Huh, Chae-Man Lim, Younsuck Koh, Sung-Han Kim, Sang-Ho Choi, Yang Soo Kim, Mi-Na Kim, Sang-Bum Hong. 2011. Relationship between the MIC of vancomycin and clinical outcome in patients with MRSA nosocomial pneumonia. Intensive Care Medicine 37:4, 639-647. [CrossRef]

3. M. E. Pachón-Ibáñez, S. Ribes, M. Á. Domínguez, R. Fernández, F. Tubau, J. Ariza, F. Gudiol, C. Cabellos. 2011. Efficacy of fosfomycin and its combination with linezolid, vancomycin and imipenem in an experimental peritonitis model caused by a Staphylococcus aureus strain with reduced susceptibility to vancomycin. European Journal of Clinical Microbiology \& Infectious Diseases 30:1, 89-95. [CrossRef]

4. S. Ribes, M. E. Pachón-Ibáñez, M. A. Domínguez, R. Fernández, F. Tubau, J. Ariza, F. Gudiol, C. Cabellos. 2010. In vitro and in vivo activities of linezolid alone and combined with vancomycin and imipenem against Staphylococcus aureus with reduced susceptibility to glycopeptides. European Journal of Clinical Microbiology \& Infectious Diseases 29:11, 1361-1367. [CrossRef]

5. Jordi Carratalà, José Alcamí, Elisa Cordero, José M. Miró, José Manuel Ramos. 2008. Investigación en enfermedades infecciosas. Enfermedades Infecciosas y Microbiología Clínica 26, 40-50. [CrossRef]

6. A. Soriano, F. Marco, J. A. Martinez, E. Pisos, M. Almela, V. P. Dimova, D. Alamo, M. Ortega, J. Lopez, J. Mensa. 2008. Influence of Vancomycin Minimum Inhibitory Concentration on the Treatment of Methicillin-Resistant Staphylococcus aureus Bacteremia. Clinical Infectious Diseases 46:2, 193-200. [CrossRef]

7. R. N. Jones. 2006. Microbiological Features of Vancomycin in the 21st Century: Minimum Inhibitory Concentration Creep, Bactericidal/Static Activity, and Applied Breakpoints to Predict Clinical Outcomes or Detect Resistant Strains. Clinical Infectious Diseases 42:Supplement 1, S13-S24. [CrossRef]

8. H SADER, T FRITSCHE, R JONES. 2005. Antimicrobial activity of daptomycin tested against clinical strains of indicated species isolated in North American medical centers (2003). Diagnostic Microbiology and Infectious Disease 53:4, 329-332. [CrossRef] 